\title{
Effect of plant protection on assemblages of ground beetles (Coleoptera, Carabidae) in pea (Pisum L.) and lupine (Lupinus L.) crops
}

\author{
AGNIESZKA KOSEWSKA ${ }^{1}$ \\ MARIUSZ NIETUPSKI ${ }^{1}$ \\ KATARZYNA NIJAK ${ }^{2}$ \\ TOMASZ SKALSKI ${ }^{3}$ \\ ${ }^{1}$ Department of Entomology, Phytopathology \\ and Molecular Diagnostic, University of Warmia \\ and Mazury, Prawocheńskiego 17, 10-719 Olsztyn \\ Poland; e-mail: a.kosewska@uwm.edu.pl \\ 2 Plant Protection Institute, Węgorka 20 \\ 60-318 Poznań, Poland; \\ ${ }^{3}$ Department of Entomology, Institute of Zoology \\ Jagiellonian University, Gronostajowa 9 \\ 30-387 Kraków, Poland.
}

\section{Correspondence:}

Agnieszka Kosewska

e-mail:a.kosewska@uwm.edu.pl

Key words: carabid beetles, crop protection, bean plants
Received January 12, 2016.

Revised June 16, 2016.

Accepted June 23, 2016

\begin{abstract}
Background and Purpose: Various crop cultivation systems may affect field-dwelling organisms, representatives of both harmful and beneficial entomofauna. In this paper, attention was drawn to one of the factors which distinguishes organic and integrated farming, that is the application of chemical plant protection preparations.
\end{abstract}

Materials and Methods: The experiment was conducted in Poland, at the Experimental Station IOR-PIB in Winna Góra near Środa Wielkopolska, on crop fields of lupine and pea. The experiment was composed of a block of organic fields (no chemical plant protection preparations) and another block, where a plant protection programme was carried out in line with the integrated agricultural production guidelines. Carabidae were caught into modified Barber traps, from May to the end of July in 2006, 2010 and 2014.

Results and conclusions: As a result of our study, 8848 specimens belonging to 67 species of Carabidae were collected. The most numerous species collected in the pea and lupine were: Poecilus cupreus, Pterostichus melanarius, Harpalus rufipes, Bembidion femoratum, Bembidion quadrimaculatum and Bembidion tetracolum. Overall, our results demonstrate that an application of chemical plant protection preparations decreases the abundance and species diversity of carabid beetles assemblages in studied crops and induces changes in particular life traits of carabids fauna. After the treatment, the abundance of large carabid beetles diminishes and their place is occupied by small zoophages. Furthermore, the forecrop could be one of the factors that influence assemblages of carabids on crop fields.

\section{INTRODUCTION}

The use of pesticides causes endless controversies. Every synthetic 1 preparation which enters the natural environment has a direct or indirect influence on many biotic elements and processes on a scale that may encompass whole ecosystems (1). Even the chemical products that do not seem toxic to humans, animals or plants can affect agricultural ecosystems adversely. The use of pesticides can have a variety of negative agricultural, environmental and health effects $(2,3,4)$. Progressive specialization in agriculture and environmental pollution due to the excessive use of chemical plant protection products has stimulated a search for pro-ecological solutions (5). Contemporary plant protection systems, on principle, should be economically efficient and eco-friendly (6). They should take advantage of all available pest-control methods while sus- 
taining natural self-regulation processes which occur in agricultural ecosystems.

Although much progress is visible in the field of plant protection products, expressed, among others in the increasing selectivity, more rapid degradation as well as the use of integrated crop protection programs, we still need to monitor the environment, particularly in terms of protecting the beneficial entomofauna occurring there. Practical application of integrated plant protection solutions involves the use - to the highest extent possible - of all alternative, non-chemical methods for elimination of agricultural pests (7). Among the most useful ways of combating plant pests, worth mentioning is crop rotation, which is essential for maintaining a healthy soil. Mass propagation of crop-specific pests can be prevented by rotating crops. Some crop species are less appealing than others as food for phytophages, and consequently, they are less attractive to their natural enemies. A possible reason could be the chemical compounds secreted by plants in response to the stress caused by foraging insects, or the compounds which are normally present in these plants (e.g. alkaloids in lupine) that deter phytophages (8). Conversely, the microclimate created by a given crop, if favourable to the development, survival and spread of entomofauna, may be responsible for the occurrence of insects $(9,10,11)$.

Crop plantations create good conditions for the development of both harmful and beneficial entomofauna. Regarding beneficial fauna, there are many parasitic and predatory insect species inhabiting agricultural ecosystems which play an important role in reducing the number of crop pests $(12 ; 13 ; 14)$. A higher number of such beneficial insects is correlated with a decrease in the number of insects potentially harmful to plants. The diversity of natural plant pest enemies is particularly valued by farmers who do not apply pesticides $(15 ; 16 ; 17)$. Epigeic carabid beetles (Col. Carabidae) are potential enemies of many plant pests $(9,18,19,20,21,22)$. The application of pesticides in crop fields and their influence on populations of Carabidae is a complex process, which should be reviewed as a product of the effects produced by many factors (9), of which an essential one is the direct impact of pesticide as a toxic substance on carabid beetles. Regarding insecticides, this interaction is more often unambiguous, i.e. the impact on these ground invertebrates is negative $(23,24)$, although the actual effect depends on factors such as: body size, ability to fly or climb plants, as well as the foraging behaviour. The influence of herbicides and fungicides is much more intricate. The actual effect they produce on Carabidae should most probably be analysed in the context of the quality and availability of plant food for herbivorous carabids and, additionally, in changes in the behaviour and habitats of ground beetles $(9,25)$. Insecticide sprays result in local abundance (12) or shortage (26) of food. The influence of food (insects killed by insecticides) remains an unanswered question.
All the above factors connected with the influence of pesticides on Carabidae may manifest themselves differently depending on the type of a crop cultivation technology, i.e. frequency of treatments, type of pesticides applied or the prohibited use of chemicals. The lack of chemical protection forces farmers to turn to other pest control methods, for example agrotechnical measures, which also affect ground beetles $(9,20,27)$.

The purpose of this study has been to determine the effect of using chemical protection on assemblages of carabid beetles occurring in pea and lupine fields grown in a four-year rotation system. The following hypotheses were made: 1) in fields with chemical protection the number and species diversity of carabids is lower than in the control fields; 2) application of chemical plant protection preparations leads to changes in some life history traits (trophic preferences and body size) of carabid beetles found in pea and lupine fields.

\section{MATERIAL AND METHODS}

The study was conducted in experimental production fields at the Experimental Station IOR-PIB in Winna Góra near Środa Wielkopolska, Poland. An experiment consisting of four-year rotations has been conducted at the station since the 1960s. This is a longitudinal field experiment, and the pattern of plots remains unchanged. It comprises two variants: I - potato, spring barley, yellow lupine and winter wheat; II - sugar beet, maize, seed pea and winter oilseed rape. The experiment is composed of a block of organic control plots, where no chemical plant protection preparations are applied (and have never been applied) and another block, where a plant protection programme is carried out in line with the integrated agricultural production guidelines prepared by the Polish Ministry of Rural Development and Agriculture (www. minrol.gov.pl). The surface of each field is 0.46 ha. The soils under the plantations are similar and belong to IIIa and IIIb class according to the Polish arable soil classification system (www. isap.sejm.gov.pl).

Ground beetles were caught in pea and lupine fields from May to the end of July during three years: 2006, 2010 and 2014. Two fields of each crop in every year of study were selected: organic $(\mathrm{O})$ and integrated $(\mathrm{C}$ - with chemical protection). During the three years chosen for our investigation, the fields under chemical protection were treated with insecticides, herbicides and fungicides, as specified in table 1. Modified Barber traps (plastic cups $10 \mathrm{~cm}$ diameter, $15 \mathrm{~cm}$ deep with ethylene glycol) were used to capture insects. Ten traps were placed in each field, at a distance of 10 meters from one another. The traps were emptied every two weeks. Thus, there were two fields in each treatment with ten traps per field as replicates. We decided to treat each trap as an independent sample because the analysis of similarity of variance between the two fields in each treatment had no significant effect of the field location on the Bray-Curtis similarity index, showing uniformity of the sampling design. 
Table 1. Characterization of the pea and lupine plantations in the consecutive years alongside the specification of pesticides applied in chemically protected fields.

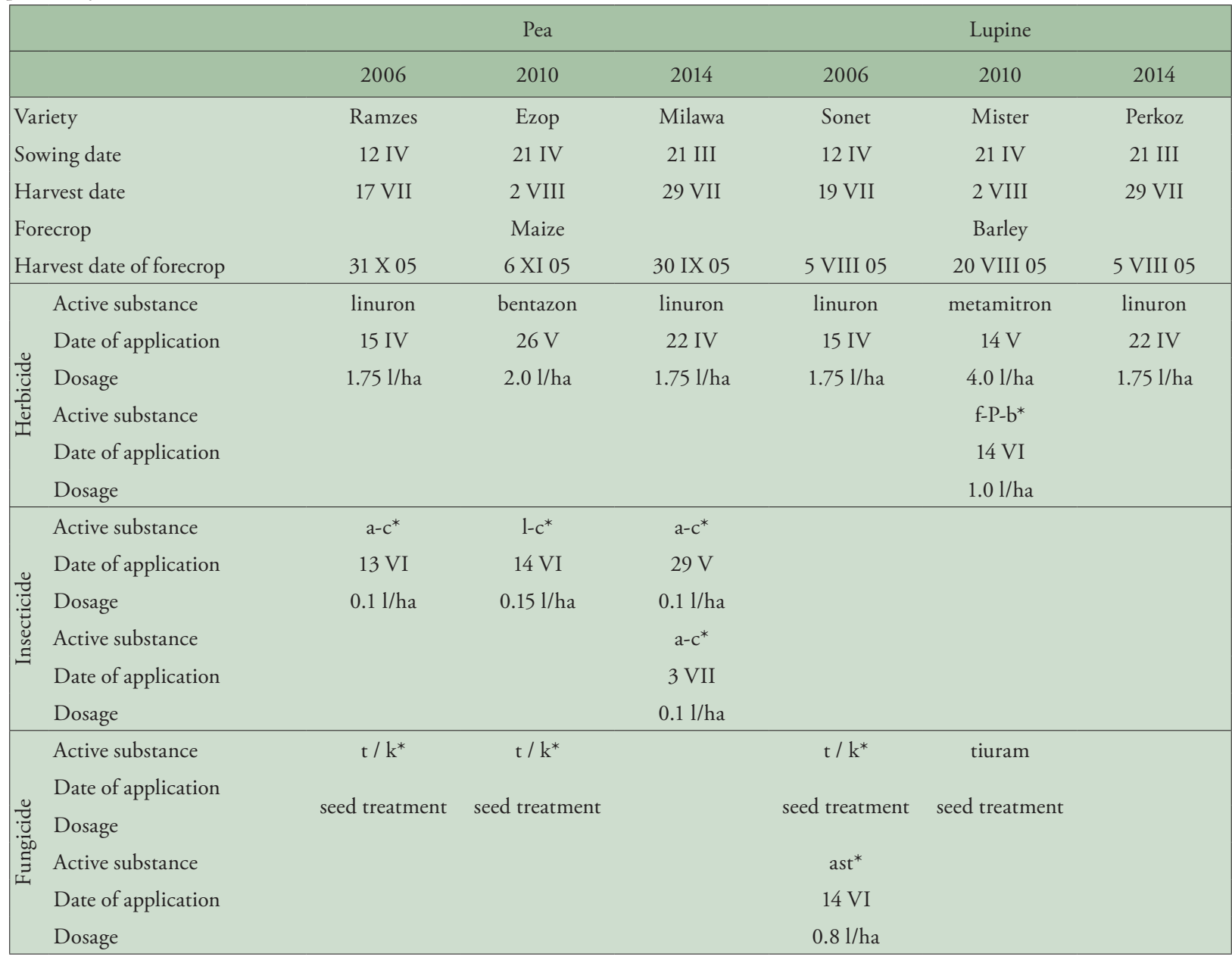

* - abbreviations of active substances: f-P-b (fluazifop-P-butyl); a-c (alpha-cypermethrin); l-c (lambda-cyhalothrin); t / k (tiuram, karbendazym); ast (azoksystrobin)

Carabidae were analyzed in terms of their species composition, abundance and richness. Because of the important role that carabid beetles play as plant pest predators, their presence was examined in respect of their feeding preferences and body size. The following groups were distinguished: hemizoophages (otherwise called omnivores, feeding a broad spectrum of food consisting of both plants and animals), large zoophages (body length more than $15 \mathrm{~mm}$ ), medium zoophages $(5.1-15 \mathrm{~mm})$, small zoophages (body length less than $5 \mathrm{~mm}$ ). The above division was based on the work presented in papers $(18,28$, 29, 30). Differences between the means were tested using a generalized linear model (GLM) with the Poisson distribution which included quantitative factors: plant protection, year of study and type of plant. Indirect ordination of carabid beetle assemblages found at the study area was performed using non-metric multidimensional scaling (NMDS). NMDS was calculated in WinKyst 1.0 (31) on a Bray-Curtis similarity matrix. To explore differences between the assemblages, analysis of similarity (ANOSIM) was employed for the sake of diagnosing the treatment effect (32). Redundancy analysis (RDA) (33) was applied to investigate correlations between the ecological groups of Carabidae and the following environmental variables: type of protection (with or without chemical plant protection), applied chemical preparations (herbicides, insecticides and fungicides), the crops and years of experiments. The RDA method was chosen following the DCA data distribution analysis, which had manifested a linear character (the gradient length $S D=2.31$ ). All statistical calculations and their graphic presentation were performed with the software programmes Statistica 10 and Canoco 4.5.

\section{RESULTS}

As a result of our study, 8848 specimens belonging to 67 species of Carabidae were collected. More specifically, 4197 specimens representing 46 species were captured in the fields with chemical plant protection, while the re- 
1a

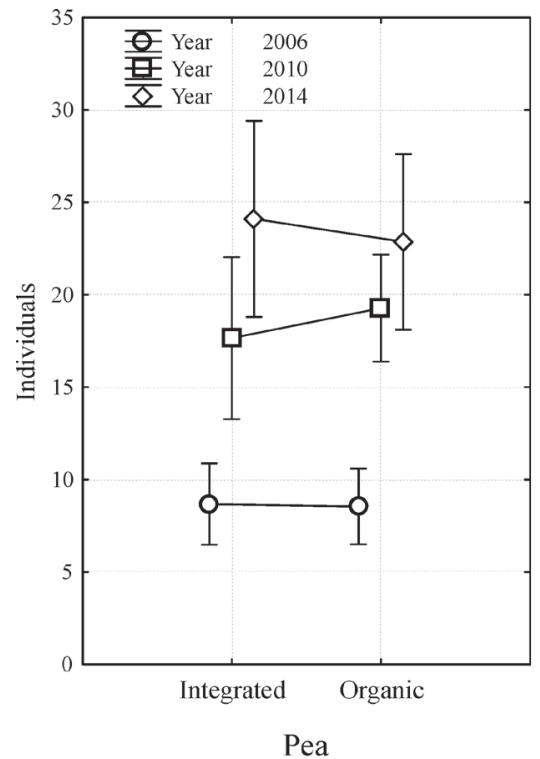

$1 b$

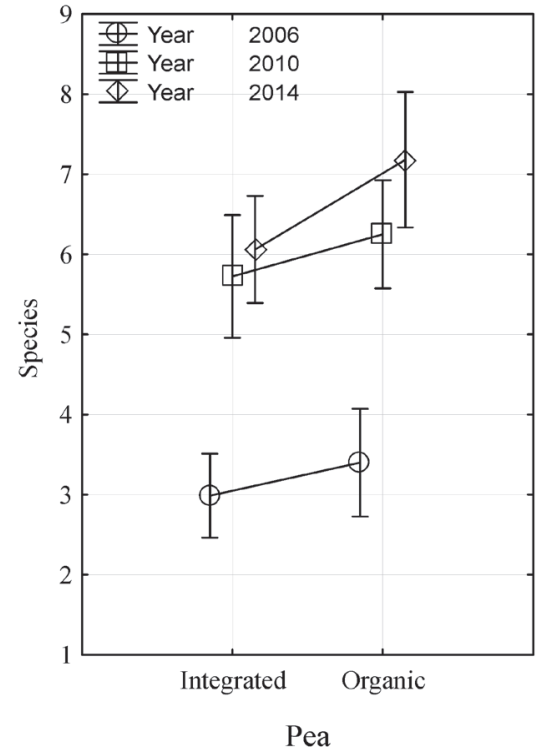

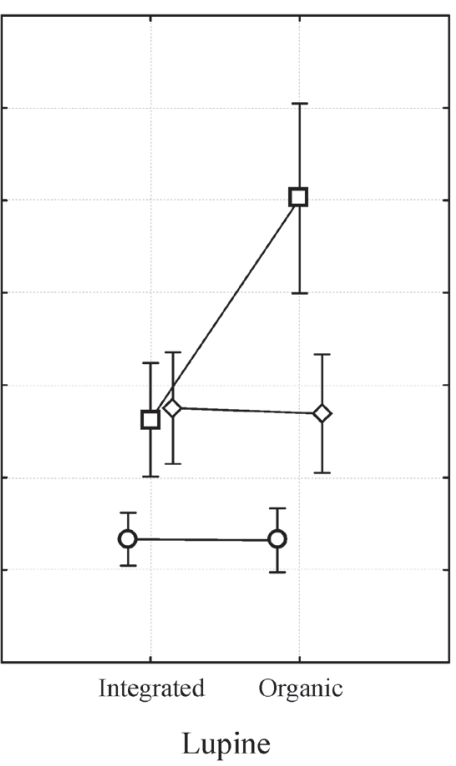

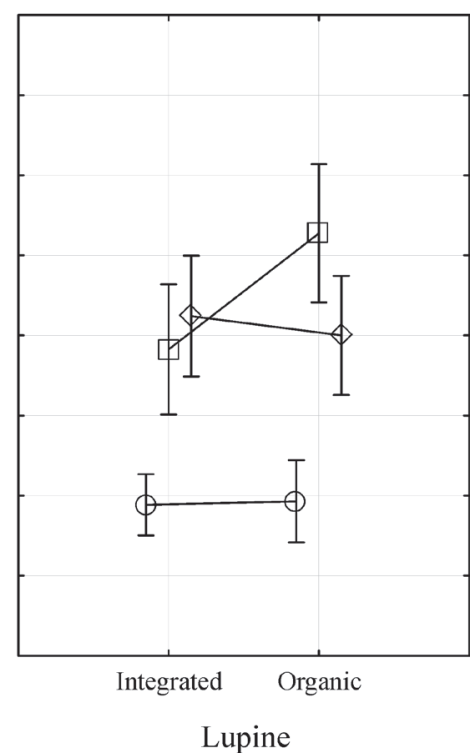

Figure 1. Average abundance (fig. 1a) and species richness (fig. 1b) of ground beetles depending on the form of plant protection (integrated, with applied of pesticides, organic - without any chemical protection) in years of study in pea and lupine crops. Vertical lines with averages mean SE.

maining 4651 individuals belonging to 59 species were trapped in organic fields. The most numerous species living in the pea and lupine fields were: Poecilus cupreus, Pterostichus melanarius, Harpalus rufipes, Bembidion femoratum, Bembidion quadrimaculatum and Bembidion tetracolum. Statistically more numerous representation of carabid specimens was observed in pea than in lupine fields (Wald's W=164.97; $\mathrm{p}<0.01$ ). While analyzing the abundance of carabids in pea and lupine plantations, both with and without applied chemical protection, a very high variation was detected depending on the year of study (Fig. 1a). Significantly more carabids were found in the lupine fields with no chemical plant protection in 2010 (Wald's W=34.19; p<0.01). Also, the other variables such as chemical plant protection, crop species as well as their interactions significantly affected carabid abundance (Table 2). The species richness was significantly affected by the above factors, although the interaction between the two variables did not have a significant influence on this characteristic (Fig. 1b, Table 2).

The NMDS analysis demonstrated a very high variation of the analyzed assemblages of ground beetles (Fig. $2 \mathrm{a}, 2 \mathrm{~b})$. Depending on the year of our study, assemblages of carabids in pea fields were highly different from one another, especially in the field treated with chemical preparations (Fig. 2a). The organic fields, irrespective of their distinctive features characteristic for each year, always contained a shared set of Carabidae. The lupine 
Table 2. Results of the GLM test of significance (Wald statistics) of the effect of the plant protection form, type of plant and year of study on abundance and species richness of ground beetle assemblages.

\begin{tabular}{|c|c|c|c|c|c|c|}
\hline & \multicolumn{3}{|c|}{ Individuals } & \multicolumn{3}{|c|}{ Species } \\
\hline & df & Wald's Stat. & $\mathrm{p}$ & df & Wald's Stat. & $\mathrm{p}$ \\
\hline Year & 2 & 1196.71 & 0.000 & 2 & 247.58 & 0.000 \\
\hline Protection & 1 & 22.75 & 0.000 & 1 & 7.60 & 0.006 \\
\hline Plant & 1 & 151.21 & 0.000 & 1 & 14.64 & 0.000 \\
\hline Year*Protection & 2 & 73.98 & 0.000 & 2 & 1.88 & 0.390 \\
\hline Year*Plant & 2 & 109.88 & 0.000 & 2 & 4.81 & 0.090 \\
\hline Protection*Plant & 1 & 19.95 & 0.000 & 1 & 0.49 & 0.485 \\
\hline Year*Protection*Plant & 2 & 34.19 & 0.000 & 2 & 5.07 & 0.079 \\
\hline
\end{tabular}

fields also presented a high variation in the composition of carabid assemblages, however the NMDS diagram does not demonstrate the spatial order of Carabidae assemblages depending on the applied plant protection system of year of study (Fig. 2b).

When analyzing the effect of the variables on the individual trophic groups, it was noticed that an application of pesticides significantly affected the abundance of such groups as large zoophages, hemizoophages and small zoophages (Table 3). A significant decrease in the number of large zoophages and hemizoophages was found in chemically protected fields, at a simultaneously increasing number of small zoophages (Fig. 3). It turned out that chemical plant protection affected significantly the abundance of all groups of carabid beetles except medium zoophages (Table 3), which in turn was significantly influenced by the year and type of crop (Fig. 3). Large zoophages proved to be sensitive to the combination of a crop field and chemical protection, to which small zoophages and hemizoophages did not respond. However, when taking into account the year of plant cultivation, these factors were also shown to affect significantly the abundance of the latter (Table 3).

The analysis of RDA demonstrated significant relationships between the analyzed assemblages of Carabidae and such environmental variables as the application of insecticides $(\mathrm{F}=21.27 ; \mathrm{p}=0.002)$, year of study $(\mathrm{F}=17.79$; $\mathrm{p}=0.002)$, application of herbicides $(\mathrm{F}=9.898 ; \mathrm{p}=0.002)$ and the form of plant protection (with or without applied chemical protection) $(\mathrm{F}=3.08 ; \mathrm{p}=0.03)$. The other vari-
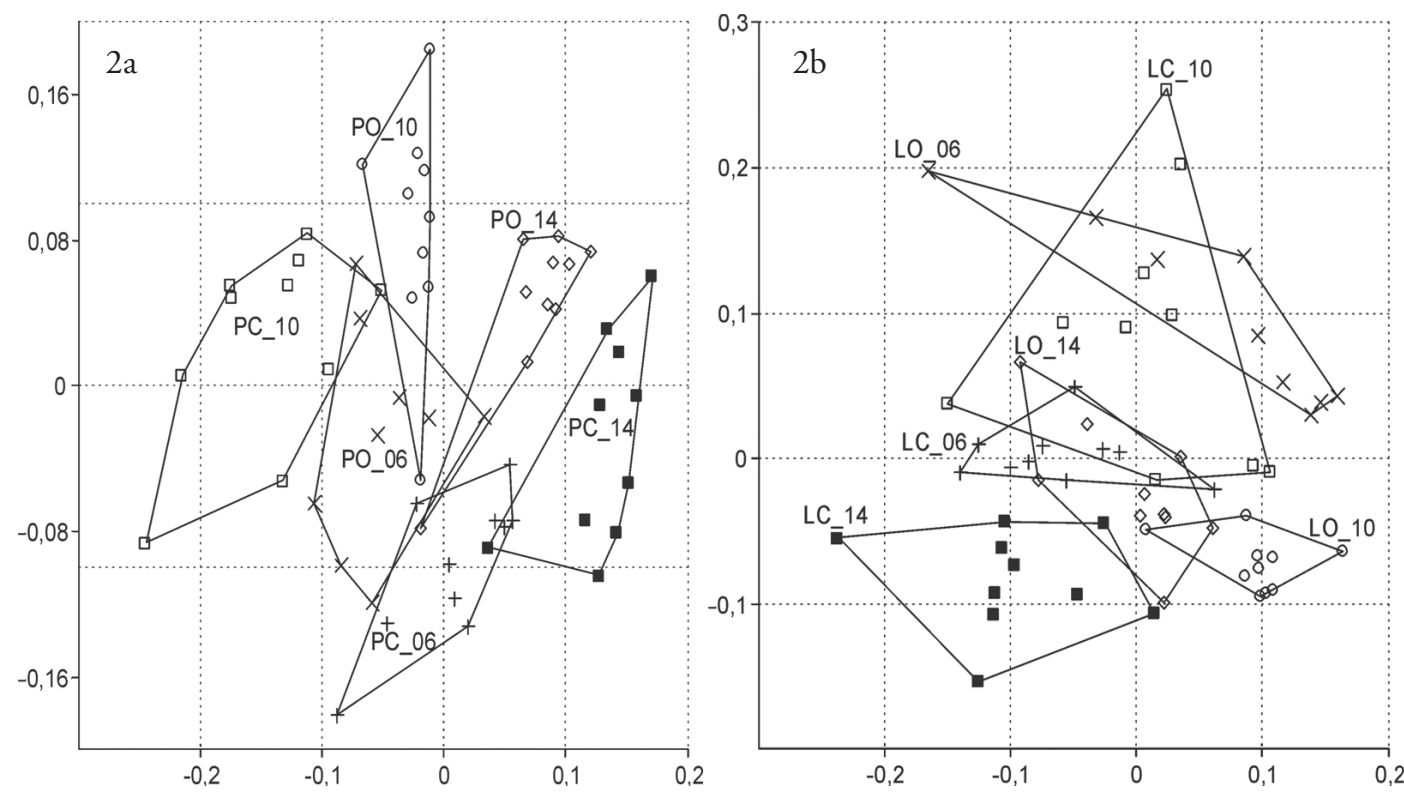

Figure 2. Diagram of non-metric multidimensional scaling (NMDS) performed on the Bray-Curtis similarity matrix of ground beetles: fig. $2 a$ - in pea crops (P), fig. $2 b$ - in lupine crops $(L)$ in years of study in different forms of plant protection $(C$ - with chemical protection, $O$ - without chemical protection) 
Table 3. Results of the GLM test of significance (Wald statistics) of the effect of the plant protection form, type of plant and year of study on body size and food preferences of ground beetle assemblages.

\begin{tabular}{|lccccccccccccccc|}
\hline & \multicolumn{3}{c}{ Large zoophages } & \multicolumn{3}{c}{ Medium zoophages } & \multicolumn{3}{c}{ Small zoophages } & \multicolumn{3}{c|}{ Hemizoophages } \\
\hline & df & Wald's Stat. & $\mathrm{p}$ & $\mathrm{df}$ & Wald's Stat. & $\mathrm{p}$ & $\mathrm{df}$ & Wald's Stat. & $\mathrm{p}$ & $\mathrm{df}$ & Wald's Stat. & $\mathrm{p}$ \\
\hline Year & 2 & 660.79 & 0.000 & 2 & 760.03 & 0.000 & 2 & 48.68 & 0.000 & 2 & 349.85 & 0.000 \\
Protection & 1 & 63.25 & 0.000 & 1 & 0.53 & 0.466 & 1 & 302.42 & 0.000 & 1 & 326.81 & 0.000 \\
Plant & 1 & 0.58 & 0.448 & 1 & 53.61 & 0.000 & 1 & 134.98 & 0.000 & 1 & 11.64 & 0.001 \\
Year*Protection & 2 & 43.79 & 0.000 & 2 & 140.60 & 0.000 & 2 & 153.87 & 0.000 & 2 & 12.63 & 0.002 \\
Year*Plant & 2 & 21.17 & 0.000 & 2 & 107.42 & 0.000 & 2 & 21.88 & 0.000 & 2 & 51.50 & 0.000 \\
Protection*Plant & 1 & 5.96 & 0.000 & 1 & 0.28 & 0.596 & 1 & 0.32 & 0.571 & 1 & 3.24 & 0.072 \\
Year*Protection*Plant & 2 & 5.90 & 0.052 & 2 & 17.00 & 0.000 & 2 & 18.39 & 0.000 & 2 & 53.21 & 0.000 \\
\hline
\end{tabular}
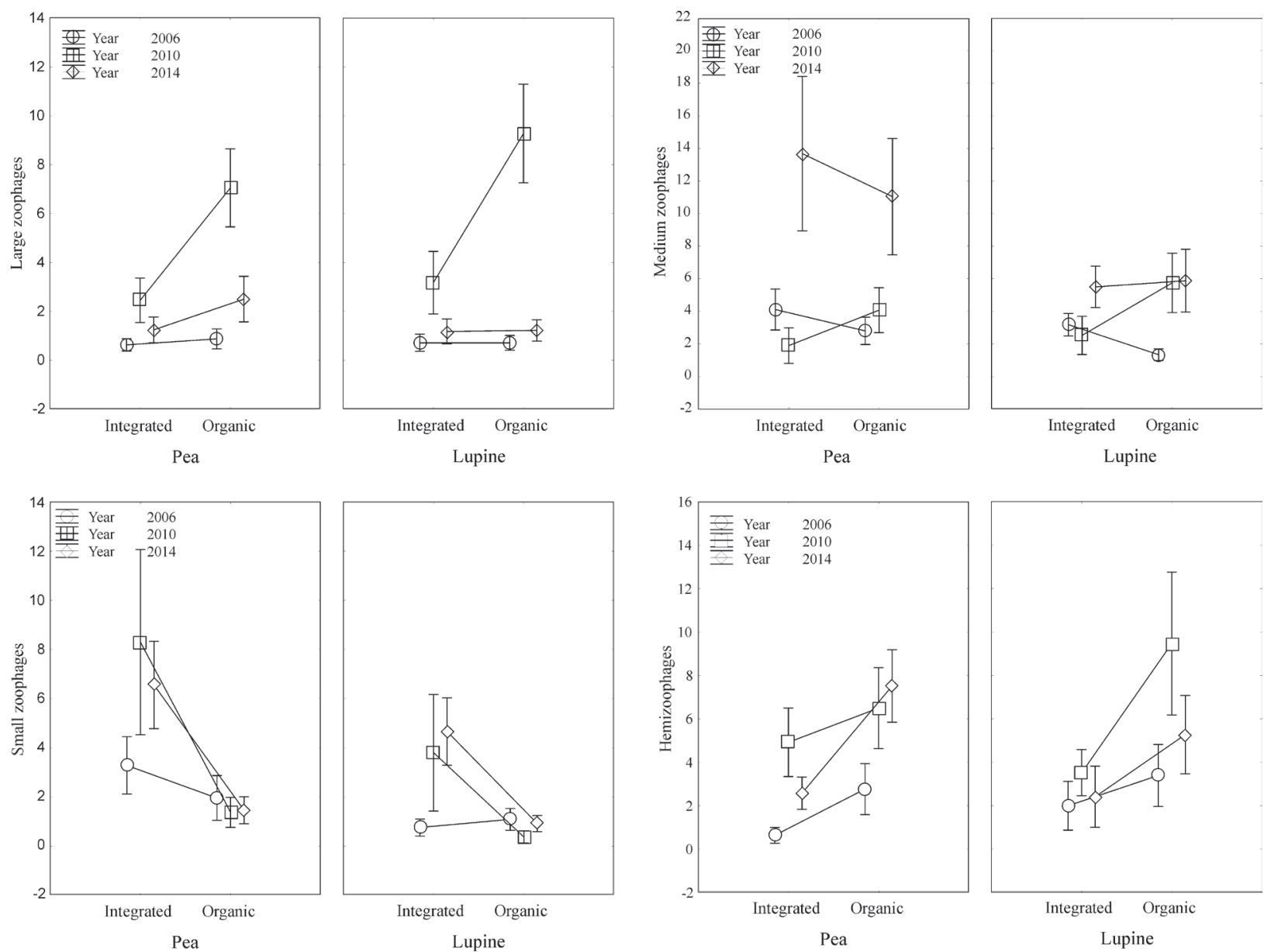

Figure 3. Average abundance of carabids belonging to different ecological groups (large zoophages, medium zoophages, small zoophages, hemizoophages) depending on the form of plant protection in years of study in pea and lupine crops. Vertical lines with averages mean SE.

ables like the crop species and application of fungicides did not produce statistically significant effects. The $1^{\text {st }}$ ordination axis, describing $70.6 \%$ of variation, was connected with the presence of medium zoophages (Fig. 4). The dominant species in the group of medium zoophages was Poecilus cupreus, which typically inhabits fields. The $2^{\text {nd }}$ ordination axis was connected with the application of herbicides. This axis described $24.6 \%$ of the variation. The application of plant protection chemicals and insecticides was correlated with the occurrence of carabids classified as small zoophages and hygrophilous species. Also, a correlation was noticed between the year of research and 


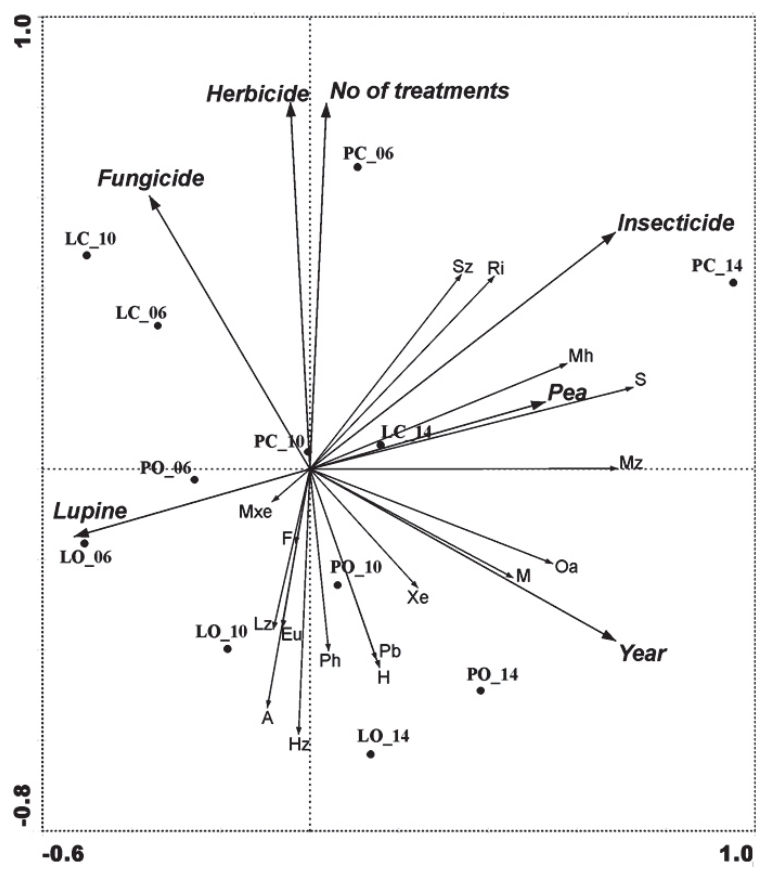

Figure 4. Diagram of the RDA demonstrating the relationships between the analyzed environmental variables (type of plant, using of insecticides, herbicides and fungicides, number of treatments and year of study) and the ecological groups of Carabidae ( $S z-$ small zoophages, $\mathrm{Mz}$ - medium zoophages, $\mathrm{Lz}$-large zoophages, $\mathrm{Hz}-$ hemizoophages, $\mathrm{Ph}$ - phytophages, $\mathrm{Oa}$ - open area, Eu - eurytopic, $P b$-peatbog, Ri-riparian, $F$-forest, $A$-autumn breeders, $S$-spring breeders, $X e$-xerophilous, $M x e-m e s o x e r o p h i l o u s, ~ M$ - mesophilous, $M h$-mesohygrophilous, $H$ - hygrophilous).

open area carabid beetles, which are most common field carabids, as well as mesophilous carabids, moderately tolerant to moist conditions. It was noticed that most of the distinguished ecological groups, such as autumn breeders, large zoophages, hemizoophages or peat-habitat species, demonstrated contrary correlations with the fields which had been chemically treated.

\section{DIsCusSION}

Crop fields are periodically suitable habitats for predatory carabids, mostly because they are inhabited by large numbers of plant pest insects, which ground beetles feed on. Farmers try to reduce as many plant pests as possible, for example by using chemical or biological crop protection technologies, crop rotation or adequate agricultural practices, but the aim remains extremely difficult to achieve, which can be proven by very high numbers of carabids in crop fields, where they are able to find enough food despite farmers' best efforts. In our study, conducted on pea and lupine fields, a high number of specimens (8 848) and species (67) of Carabidae was collected. The species composition in fields we studied showed that the dominant epigeic carabid species were the ones typical of agricultural fields in Europe, irrespective of the crop spe- cies grown, (18), i.e. Poecilus cupreus, Pterostichus melanarius, and Harpalus rufipes. These species are quite large representatives of Carabidae. Their average body length is 12.4, 15.7 and $13.4 \mathrm{~mm}$, respectively (34), which explains their high efficiency in eating plant pest insects. Although H. rufipes is classified as a hemizoophage, feeding on mixed plant and animal food, its considerable size coupled with a numerous occurrence can contribute to a notable reduction of the gradation of unwanted insects in plant fields. In our study, similarly to the results reported by Shah et al. (35) but contrary to the study conducted by Eyre et al. (36), P. melanarius occurred more numerously in fields without chemical protection. Likewise, H. rufipes was more abundant in fields without chemical protection. However, the third dominant species mentioned, $P$. cupreus, appeared to be more numerous in fields with chemical plant protection treatments. It is worth noticing that the time of trap exposure (from May to end of July) could promote a more numerous catch of ground beetles representing the spring type of development.

Several researchers (e.g. 10, 37, 38) suggest that the abundance and composition of assemblages of ground beetles can be affected by highly diverse factors, and their abundance differs both between fields and between years. In this study, differences in the number of individuals and species richness of carabids in the particular years analyzed were distinctly manifested. Some authors (9, 18, 39, 40) highlight the effect of crops on carabid beetles. The number of ground beetles can be reduced or stimulated by such factors as soil cultivation, other agricultural technologies, the preceding crop or the density of crop stand (36, 41, 42, 43). In Europe, fields of the Fabaceae have been relatively infrequently studied in terms of the presence of carabids $(10,21,44,45)$. Our study demonstrated a higher abundance of ground beetles in pea than in lupine fields. According to Kordan et al. (46), pea is more vulnerable to infestation, for example by aphids, which means they offer a better food supply for carabids than lupine fields. Because the type of crops and applied agricultural technologies were similar, it is worth paying attention to the preceding crops. The experiment was based on four-year rotation, and therefore a pea field was always preceded by maize while a lupine field was set up following spring barley. Such factor as the harvest date may also play a role. Spring barley was cut in August whereas maize remained on a field for at least another two months. Pea cultivation was correlated with a more numerous presence of spring breeders (Fig. 4). This may have resulted from the type of the crop preceding pea, which was maize. Maize was harvested for dry kernels, which means it was left on a field until late autumn and its harvest was followed by pre-winter soil ploughing. When field cultivation treatments like this are carried out very late in a year, they seriously disturb wintering larvae of Carabidae (autumn breeders) and predispose a field to a more abundant presence of species which winter as adults. 
Another significant factor influencing carabid assemblages is the application of chemical plant protection preparations $(18,47,48,49,50,51)$. Most often, the negative effect of pesticides on the number of individuals and species richness is implicated $(35,52,53)$. Unsurprisingly, this research also demonstrated that the applied chemical plant protection treatments in pea and lupine fields found their negative manifestation in the species richness of $\mathrm{Ca}$ rabidae assemblages living in these fields. However, with respect to the number of individuals, especially in pea fields, no differences appeared between the organic and chemically treated fields. It may seem that the application of pesticides did not have an adverse impact on the abundance of ground beetles. However, when we trace the presence of individual trophic groups in the experimental fields, we notice a distinctly negative effect of the applied pesticides on the number of large zoophages and hemizoophages, while the number of small zoophages was rising. Thus, it can be suggested that large zoophages are very sensitive to pesticide application. After their elimination, competitive interactions between predators are weaker, and the rate of recolonization by small zoophages, which have high dispersal power, increases. At full chemical protection of fields, which was implemented in pea fields (application of herbicides, fungicides and insecticides), they reached similar abundance in both types of fields (chemically protected and without chemical protection ones). Most probably, once the species competition in the form of large zoophages had been removed, their place was occupied by small zoophages. Similar conclusions on rapid recolonization of fields after an application of pesticides by other groups of Carabidae than present in these fields before the chemical treatment have been drawn by Basedow et al. (48) and Shah et al. (35). Also, the RDA results indicate that there is a significant correlation between the presence of carabids classified as small zoophages and an application of insecticides. It should therefore be resolved whether the success of small zoophages in fields with chemical plant protection results from their higher resistance to chemical substances or from the weaker competition on behalf of other insects due to the application of pesticides and elimination of better competitors such as large zoophages. The density of Bembidion lampros in laboratory conditions is pesticide dependent (54). High sensitivity of Bembidion obtusum to a laboratory application of Pirimicarb insecticide was proven by Cilgi et al. (55). The negative influence of an application of chemical plant protection preparations on small zoophages (Epaphius secalis and Bembidion guttula) was also observed in field experiments (52). But in that case, the timing of the application of chemicals and breeding strategy may reduce the negative effect. Early spring application of pesticide in a field has no negative effect on the population density of small zoophages (54). The seasonal activity of spring breeders and spring application of pesticides significantly increase the risk of mortality among small zoophages (52). However, small zoophages are flying insects and, after the disturbance caused by an application of sprayed chemi- cals, they are able to recolonize the affected field more rapidly (56). A similar exchange of species can be observed in assemblages exposed to other types of destructive influence, e.g. in forests, in degraded areas (57), under the effect of chronic heavy metal contamination $(58,59)$ or natural fluctuations of the water table in rivers $(60,61)$, as well as due to a complex impact of people on urban landscapes (62). This type of species will not constitute an effective barrier to the occurrence of pest insects because their presence is sporadic and shaped by migratory conditions, and not by their resistance to pesticides and stability in agricultural ecosystem.

\section{CONCLUSIONS}

The application of chemical plant protection preparations has decreased the abundance and species diversity of carabid beetles in legume fields. The application of pesticides induces changes in the Carabidae fauna in crop fields. After their application, the abundance of large carabid beetles diminishes and their place is occupied by small zoophages. Furthermore, the forecrop could be one of the factors influencing assemblages of carabids on crop fields.

\section{REFERENCES}

1. WALKER C H, HOPKIN S P, SIBLY R M, PEAKALL D B 2001 Principles of Ecotoxicology. Taylor \& Francis. New York, p 301

2. SMITH T M, STRATTON G W 1986 Effects of synthetic pyrethroid insecticides on nontarget organisms. Residue Revues 97: 93-120 http://dx.doi.org/10.1007/978-1-4612-4934-4_4

3. GROGAN K A 2014 When ignorance is not bliss: Pest control decisions involving beneficial insects. Ecol Econ 107: 104-113 http://dx.doi.org/10.1016/j.ecolecon.2014.08.007

4. AKKÖPRÜ E P, ATLIHAM R, OKUT H, CHI H 2015 Demographic Assessment of Plant Cultivar Resistance to Insect Pests: A Case Study of the Dusky-Veined Walnut Aphid (Hemiptera: Callaphididae) on Five Walnut Cultivars. J Econ Entomol: 1-10

5. STĘPIEŃ A, WOJTKOWIAK K 2013 Composition of gluten proteins in spring and winter wheat grain cultivated under conditions of varied fertilization. Acta Agr Scand B-S P 63 (7): 588-594 http://dx.doi.org/10.1080/09064710.2013.829866

6. BURLYAY A, BURLYAY A, KHARENKO A 2015 Peculiarities of costs formation in the organic crop production yielding. Economic Annals-XXI 3-4 (2): 29-32

7. OLLE M, TSAHKNA A, TÄHTJÄRV T, WILLIAMS I H 2015 Plant protection for organically grown potatoes $-\mathrm{A}$ review. Biol Agric Hortic 31(3): 147-157

http://dx.doi.org/10.1080/01448765.2014.983546

8. KORDAN B, DANCEWICZ K, WRÓBLEWSKA A, GABRYŚ B 2012 Intraspecific variation in alkaloid profile of four lupine species with implications for the pea aphid probing behaviour. Phytochem Lett 5: 71-77 http://dx.doi.org/10.1016/j.phytol.2011.10.003

9. HOLLAND J M, LUFF M L 2000 The effects of agricultural practices on Carabidae in tem-perate agroecosystems. Integr Pest Manag Rev 5: 109-129 http://dx.doi.org/10.1023/A:1009619309424

10. HATTEN T D, BOSQUE-PÉREZ N A, JOHNSON-MAYNARD J, EIGENBRODE S D 2007 Tillage differentially affects the capture rate of pitfall traps for three species of carabid beetles. Entomol Exp Appl 124: 177-187 
11. FERNANDEZ D E, CICHON L I, SANCHEZ E E, GARRIDO $S$ A, GILTINS C 2008 Effect of different cover crops on the presence of arthropods in an organic apple (Malus domestica Borkh) orchard. J Sustain Agr 32 (2): 197-211

12. SĄDEJ W, NIETUPSKI M 2000 Occurrence of pea aphid (Acyrthosiphon pisum Harris) on faba bean and some biotic factors reducing its numbers. Natural Science 5: 73-82

13. BIRKHOFER K, FLIESBACH A, WISE D H, SCHEU S 2008 Generalist predators in organically and conventionally managed grass-clover fields: implications for conservation biological control. Ann Appl Biol 153: 271-280

14. EYRE M D, SANDERSON R A, SHOTTON P N, LEIFERT C 2009 Investigating the effects of crop type, fertility management and crop protection on the activity of beneficial invertebrates in an extensive farm management comparison trial. Ann Appl Biol 155: 267-276

15. DUELLI P, OBRIST M K, SCHMATZ D R 1999 Biodiversity evaluation in agricultural landscapes: above-ground insects. Agric Ecosyst Environ 74: 33-64 http://dx.doi.org/10.1016/S0167-8809(99)00029-8

16. SUNDERLAND K D 2002 Invertebrate pest control by carabids. In: Holland J. M. (ed.): The agroecology of Carabid Beetles. Intercept, Andover, p 165-214

17. WEIBULL A C, ÖSTMAN O, GRANQVIST A 2003 Species richness in agroecosystems: the effect of landscape, habitat and farm management. Biodivers Conserv 12: 1335-1355

18. THIELE H U 1977 Carabid Beetles in their Environments. A Study on Habitat Selection by Adaptation in Physiology and Behavior. Zoophysiology and Ecology 10. Springer Verlag, Berlin, pp 369

19. LÖVEI G L, SUNDERLAND K D 1996 Ecology and behavior of ground beetles (Coleoptera: Carabidae). Annu Rev Entomol 41: 231-256 http://dx.doi.org/10.1146/annurev.en.41.010196.001311

20. KROMP B 1999 Carabid beetles in sustainable agriculture: a review of pest control efficacy, cultivation impact and enhancement. Agr Ecosyst Environ 74: 187-228 http://dx.doi.org/10.1016/S0167-8809(99)00037-7

21. HUREJ M, TWARDOWSKI J 2006 The influence of yellow lupin intercropped with spring triticale on predatory carabid beetles ( $\mathrm{Co}$ leoptera: Carabidae). Eur J Entomol 103: 259-261 http://dx.doi.org/10.14411/eje.2006.031

22. KOSEWSKA A, SKALSKI T, NIETUPSKI M 2014 Effect of conventional and non-inversion tillage systems on the abundance and some life history traits of carabid beetles (Coleoptera: Carabidae) in winter triticale fields. Eur J Entomol 111(5): 669-676 http://dx.doi.org/10.14411/eje.2014.078

23. EPSTEIN D L, ZACK R S, BRUNNER J F, GUT L, BROWN J J 2001 Ground beetle activity in apple orchards under reduced pesticide management regimes. Biol Control 21 (2): 97-104

24. FUNAYAMA K 2011 Influence of pest control pressure on occurrence of ground beetles (Coleoptera: Carabidae) in apple orchards. Appl Entomol Zool 46 (1): 103-110 http://dx.doi.org/10.1007/s13355-010-0015-9

25. EVANS S C, SHAW E M, RYPSTRA A L 2010 Exposure to a glyphosate-based herbicide affects agrobiont predatory arthropod behaviour and long-term survival. Ecotoxicology 19: 1249-1257 http://dx.doi.org/10.1007/s10646-010-0509-9

26. FRAMPTON G K, CILGI T 1994 Long-term effects of pesticides on Carabidae in U.K. farmland: some initial results from the "SCARAB" Project. In: Desender K, Dufrene M, Loreau M, Luff M L, Maelfait J P (eds): Carabid Beetles: Ecology and Evolution. Kluwer, Dordrecht 433-438

27. COLE L J, MCCRACKEN D I, DOWNIE I S, DENNIS P, FOSTER G N, WATERHOUSE T, MURPHY K J, GRIFFIN A L, KENNEDY M P 2005 Comparing the effects of farming practices on ground beetle (Coleoptera: Carabidae) and spider (Araneae) assemblages of Scottish farmland. Biodiversity and Conservation 14: 441-46 http://dx.doi.org/10.1007/s10531-004-6404-z
28. LINDROTH C H 1985 The Carabidae (Coleoptera) of Fennoscandia and Denmark. Fauna Entomol Scandinavica 15: 1-225

29. LINDROTH C H 1986 The Carabidae (Coleoptera) of Fennoscandia and Denmark. Fauna Entomol Scandinavica 15: 230-497

30. ALEKSANDROWICZ O R 2004 Biegaczowate (Carabidae). In: Bogdanowicz W., Chudziaka E., Filipiuk I., Skibińska E. (Eds.). Fauna Polski - charakterystyka i wykaz gatunków. Muzeum i Instytut Zoologii PAN. Warszawa I: p 28-42

31. ŠMILAUER P 2002 WinKyst 1.0, Ceske Budejovice, Czech Republic

32. ANDERSON M 2001 A new method for non-parametric multivariate analysis of variance. Austral Ecol, 26: 32-46 http://dx.doi.org/10.1046/j.1442-9993.2001.01070.x

33. TER BRAAK C J F, ŠMILAUER P 1998 CANOCO Reference Manual and User's Guide to Canoco for Windows. Microcomputer Power, Ithaca, USA, p 352

34. HŮRKA K 1996 Carabidae of the Czech and Slovak Republics. Kabournek - Zlin, pp 565

35. SHAH P A, BROOKS D R, ASHBY J E, PERRY J N, WOIWOD I P 2003 Diversity and abundance of the coleopteran fauna from organic and conventional management systems in southern England. Agric Forest Entomol 5: 51-60 http://dx.doi.org/10.1046/j.1461-9563.2003.00162.x

36. EYRE M D, LUFF M L, LEIFERT C 2013 Crop, field boundary, productivity and disturbance influences on ground beetles (Coleoptera, Carabidae) in the agroecosystem. Agr Ecosyst Environ 165: 60-67

37. HANCE T, GREGOIRE-WIBO C, LEBRUN P 1990 Agriculture and ground beetle populations. Pedobiologia 34: 337-346

38. HOLLAND J M, COOK S K, DRYSDALE A, HEWITT M V, SPINK J, TURLEY D 1998 The impact on non-target arthropods of integrated compared to conventional farming: results from the LINK Integrated Farming Systems Project. Brighton Crop Protection Conference - Pests and Disease 2: 625-630

39. KABACIK-WASYLIK D 1970 Ökologische Analyse der Laufkäfer (Carabidae) einiger Agrarkulturen. Ekol Pol (A) 18: 137-209

40. MELNYCHUK N A, OLFERT O, YOUNGS B, GILLOTT C 2003 Abundance and diversity of Carabidae (Coleoptera) in different farming systems. Agr Ecosyst Environ 95: 69-72

41. HANCE T 2002 Impact of cultivation and crop husbandry practices. In: Holland J.M. (ed). The Agroecology of Carabid Beetles. Intercept, Andover, UK: p 231-250

42. HOLLAND J M, REYNOLDS C J M 2003 The impact of soil cultivation on arthropod (Coleoptera and Araneae) emergence on arable land. Pedobiologia 47: 181-191 http://dx.doi.org/10.1078/0031-4056-00181

43. SKŁODOWSKI J J 2014 Effects of top-soil preparation and broadleaved tree mixture on carabid beetles in afforested fallow plots. Restor Ecol 22: 13-21 http://dx.doi.org/10.1111/rec.12034

44. OLBRYCHT T, JAWORSKA T 2000 The ground beetles (Coleoptera, Carabidae) fauna on Papilionaceous plants in Rzeszów region. Prog. Plant Prot./Post. Ochr. Roślin 40(2): 520-522

45. OLBRYCHT T, WIECH K 2004 The composition of carabid and rove beetle species occurring in mixed cropping of some legumes and small grains. Prog. Plant Prot./Post. Ochr. Roślin 44(2): $994-$ 997

46. KORDAN B, GABRYŚ B, DANCEWICZ K, LAHUTA LB, PIOTROWICZ-CIEŚLAK A, ROWIŃSKA E 2008 European yellow lupine, Lupinus luteus, and narrow-leaf lupine, Lupinus angustifolius, as hosts for the pea aphid, Acyrthosiphon pisum. Entomol Exp Appl 128: 139-146 http://dx.doi.org/10.1111/j.1570-7458.2008.00702.x

47. NOVÂK K, SKUHRAVY V 1957 Der Einfluß von DDT. In: Aerosolform auf einige Insektenarten des Kartoffelfeldes. Zool Listy 6: 41-51

48. BASEDOW T, BORG A, SCHERNEY F 1976 Auswirkungen von Insektizidbehandlungen auf die epigäischen Raubarthropoden in 
Getreidefeldern, insbesondere die Laufkäfer (Coleoptera, Carabidae). Entomol Exp Appl 19: 37-51

http://dx.doi.org/10.1111/j.1570-7458.1976.tb02579.x

49. VICKERMAN G P, COOMBES D S, TURNER G, MEADBRIGGS M, EDWARDS J 1987 The effects of pirimicarb, dimethoate and deltamethrin on Carabidae and Staphylinidae in winter wheat. Mededelingen Facultat Landbouwwhogeschool Rijksuniversitat Gent 52: 213-223

50. FLOATE K D, ELLIOTT R H, DOANE J F, GILLOTT C 1989 Field bioassay to evaluate contact and residual toxicities of insecticides to carabid beetles (Coleoptera: Carabidae). J Econ Entomol 82: $1543-1547$

51. PURVIS G, FADL A 2002 The influence of cropping rotations and soil cultivation practice on the population ecology of carabids (Coleoptera: Carabidae) in arable land. Pedobiologia 46: 452-474 http://dx.doi.org/10.1078/0031-4056-00152

52. HUUSELA-VESITOLA E 1996 Effects of pesticide use and cultivation techniques on ground beetles (Col., Carabidae) in cereal fields. Ann Zool Fenn 33: 197-205

53. HOLLAND J M 1998 Comparative impact of insecticide treatments on beneficial invertebrates in conventional and integrated farming systems. In: P.T. Haskell and P. McEwen $(e d s)$ Ecotoxicology: Pesticides and Beneficial Organisms: p 267-78 http://dx.doi.org/10.1007/978-1-4615-5791-3_28

54. OBADOFON A, FINLAYSON D G 1977 Interactions of several insecticides and a carabid predator (Bembidion lampros (Hrbst.)) and their effects on Hylemya brassicae (Bouch). Can J Plant Sci, p 1121-1126 http://dx.doi.org/10.4141/cjps77-166

Appendix A. List of caught carabid species and their ecological description (abbreviations are given in fig. 4). Agonum fuliginosum (Panzer, 1809) Eu/H/Mz/S; Agonum mueleri (Herbst, 1784) Oa/Mh/ $\mathrm{Mz} / \mathrm{S}$; Agonum sexpunctatum (Linnaeus, 1758) Oa/Mh/Mz/S; Amara aenea (De Geer, 1744) Oa/Xe/Ph/S; Amara bifrons (Gyllenhal, 1810) Oa/Mxe/Hz/A; Amara brunnea (Gyllenhal, 1810) F/M/Hz/A; Amara communis (Panzer, 1797) Oa/M/Hz/S; Amara convexior Stephens, $1828 \mathrm{Oa} / \mathrm{M} / \mathrm{Hz} / \mathrm{S}$; Amara curta Dejean, 1828 Oa/Mxe/Hz/S; Amara familiaris (Duftschmidt, 1812) Eu/M/Hz/S; Amara ingenua (Duftschmid, 1812) Oa/M/Hz/A; Amara littorea Thomson, $1857 \mathrm{Oa} / \mathrm{M} / \mathrm{Hz} / \mathrm{S}$; Amara lunicollis Schiodte, 1837 Oa/M/Hz/S; Amara ovata (Fabricius, 1792) Oa/Mxe/Hz/S; Amara plebeja (Gyllenhal, 1810) Oa/Mh/Ph/S; Amara similata (Gyllenhal, 1810) Oa/M/Ph/S; Amara spreta (Dejean, 1831) Oa/Mxel $\mathrm{Hz} / \mathrm{S}$; Anchomenus dorsalis (Pontoppidan, 1763) Oa/Mh/Mz/S; Anisodactylus binotatus (Fabricius, 1787) Oa/Mh/Hz/S; Asaphidion flavipes (Linnaeus, 1761) Eu/Mh/Sz/S; Bembidion femoratum (Strum, 1825) Ri/Mb/Sz/S; Metallina lampros (Herbst, 1784) Oa/M/Sz/S; Metallina properans (Stephens, 1828) Oa/M/Sz/S; Bembidion quadrimaculatum (Linnaeus, 1761) Oa/M/Sz/S; Bembidion tetracolum Say, 1823 Ri/Mb/Sz/S; Blethisa multipunctata (Linnaeus, 1758) Ri/H/Mz/S; Bradycellus harpalinus (AudinetServille, 1821) Oa/Mxe/Hz/S; Broscus cephalotes (Linnaeus, 1758) Oa/Xe/Lz/A; Calathus ambiguus (Paykull, 1790) Oa/Mxe/Mz/A; Calathus cinctus (Motschulsky, 1850) Oa/Mxe/Mz/A; Calathus erratus (Sablberg, 1827) F/Mxe/Mz/A; Calathus fuscipes (Goeze, 1777) Oa/M/Mz/A; Calathus halensis (Schaller, 1783) Oa/M/Lz/A;
55. CILGI T, WRATTEN S D, ROBERTSON J L, TURNER D E, HOLLAND J M, FRAMPTON G K 1996 Residual toxicities of three insecticides to four species (Coleoptera: Carabidae) of arthropod predator. Can Entomol 128: 1115-1124 http://dx.doi.org/10.4039/Ent1281115-6

56. NAVNTOFT S, ESBJERG P, RIEDEL W, 2006 Effects of reduced pesticide dosages on carabids (Cleoptera: Carabidae) in winter wheat. Agr Forest Entomol 8: 57-62 http://dx.doi.org/10.1111/j.1461-9555.2006.00282.x

57. SCHWERK A, SZYSZKO J 2011 Model of succession in degraded areas based on carabid beetles (Coleoptera, Carabidae). ZooKeys 100: 319-332 http://dx.doi.org/10.3897/zookeys.100.1534

58. SKALSKI T, KRAMARZ P, LASKOWSKI R, STONE D 2010 Ground beetle community responses to heavy metal pollution. Baltic Journal of Coleopterology 10: 1-12

59. SKALSKI T, KĘDZIOR R, KNUTELSKI S 2015 Ground beetles as indicators of heavy metal pollution in forests. Sylwan 159 (11): 905-911

60. RADECKI-PAWLIK A, SKALSKI T 2008 Bankfull discharge determination using the new Invertebrate Bankfull Assessment Method. Journal of Water and Land Development 12: 145-153 http://dx.doi.org/10.2478/v10025-009-0011-z

61. SIENKIEWICZ P, ŻMIHORSKI M 2013 The effect of disturbance caused by rivers flooding on ground beetles (Coleoptera: Carabidae), Eur J Entomol 109 (4): 535-541 http://dx.doi.org/10.14411/eje.2012.067

62. MAGURA T, TÓTHMÉRÉSZ B, LÖVEI G L 2006 Body size inequality of carabids along an urbanisation gradient. Basic Appl Ecol 7: 472-482 http://dx.doi.org/10.1016/j.baae.2005.08.005

Calathus melanocephalus (Linnaeus, 1758) Oa/M/Mz/A; Calosoma auropunctatum (Herbst, 1784) Oa/M/Lz/A; Carabus cancellatus Illiger, 1798 Eu/M/Lz/S; Carabus nemoralis O.F.Muller, 1764 Eu/M/Lz/S; Cicindela hybrida Linnaeus, 1758 Oa/Xe/Lz/S; Clivina fossor (Linnaeus, 1758) Oa/M/Mz/S; Curtonotus aulicus (Panzer, 1797) Oa/M/Hz/A; Dyschirius politus (Dejean, 1825) Ri/H/ Sz/S; Dyschirius globosus (Herbst, 1784) Oa/Mb/Sz/S; Harpalus affinis (Schrank, 1781) Eu/Mxe/Hz/S; Harpalus distinguendus (Duftschmid, 1812) Oa/Xe/Hz/S; Harpalus griseus (Duftschmid, 1812) Oa/Xe/Hz/A; Harpalus luteicornis (Duftschmid, 1812) $\mathrm{Oa} / \mathrm{M} / \mathrm{Hz} / \mathrm{S}$; Harpalus laevipes Zetterstedt, $1828 \mathrm{~F} / \mathrm{M} / \mathrm{Hz} / \mathrm{S}$; Harpalus rubripes (Duftschmid, 1812) Oa/Mxe/Hz/S; Harpalus rufipes (De Geer, 1744) Oa/M/Hz/A; Harpalus signaticornis (Duftschmid, 1812) Oa/Mxe/Hz/S; Harpalus smaragdinus (Duftschmid, 1812) Oa/Xe/Hz/S; Harpalus tardus (Panzer, 1797) Oa/Mxe/Hz/S; Loricera pilicornis (Fabricius, 1775) Pb/H/Mz/S; Microlestes minutulus (Goeze, 1777) Eu/Mxe/Sz/S; Notiophilus palustris (Duftschmid, 1812) Oa/M/Sz/S; Ophonus rufibarbis (Fabricius, 1792) Eu/M/Mz/A; Poecilus cupreus (Linnaeus, 1758) Oa/M/Mz/S; Poecilus lepidus (Leske, 1758) Oa/Xe/Mz/S; Poecilus punctulatus (Schaller, 1783) Oa/Xe/Lz/S; Poecilus versicolor (Sturm, 1824) Oa/M/Mz/S; Pterostihus melanarius (Illiger, 1798) Eu/M/Lz/A; Pterostichus oblongopunctatus (Fabricius, 1787) F/M/ Mz/S; Syntomus truncatellus (Linnaeus, 1761) Oa/Mxe/Sz/S; Synuchus vivalis (Illiger, 1798) Oa/Mxe/Mz/A; Trechoblemus micros (Herbst, 1784) Oa/Mxe/Sz/S; Trechus quadristriatus (Schrank, 1781) Oa/Mxe/Sz/A; Zabrus tenebrioides Oa/Mxe/Lz/A; 